\title{
The Effect of Peer Instruction Method on Pre-Service Teachers' Conceptual Comprehension of Methodology Course
}

\author{
Safaa Mohammad Al-Hebaishi ${ }^{1}$ \\ ${ }^{1}$ Taiba University, Medina, Saudi Arabia \\ Correspondence: Safaa Mohammad Al-Hebaishi, Taiba University, Medina, Saudi Arabia. E-mail: \\ dr.safaa93@yahoo.com \\ Received: February 22, 2017 \\ Accepted: March 4, 2017 \\ Online Published: March 15, 2017 \\ doi:10.5539/jel.v6n3p70 \\ URL: http://doi.org/10.5539/jel.v6n3p70
}

\begin{abstract}
Peer teaching has become a productive learning strategy at all education levels. Peer Instruction Method is carried out in a range of forms and contexts like co-tutoring, reciprocal tutoring and discussion groups without teachers. To examine the effectiveness of using the peer instruction method to enhance the conceptual comprehension of pre-service teachers' attending a methodology course. The participants included 78 female post-graduate English teachers, who were seeking to obtain their teaching qualifications and were enrolled in a teaching methodology course during the first semester of the 2015 academic year. Statistically significant differences were observed while examining peer instruction method and students' achievements $(\mathrm{t}=.181$; sig $=.857$ ). Higher score ranging from 4.5500 and 3.4000 was observed among students in regards of peer instruction method. It has been examined that lecture enjoyability is increased from peer instruction method. Students are more perceived towards making apparent viewpoints concerning course concepts. Peer instruction method positively influence on attitudes of treatment group to understand essential course concepts. Peer instruction method was effective in enhancing conceptual comprehension and that the participants harboured positive attitudes towards it.
\end{abstract}

Keywords: attitudes, conceptual comprehension, conceptual learning, methodology courses, language, pre-service teachers

\section{Introduction}

Learning is an active and dynamic process where individuals learn through work, practice, and experience rather than through memorization or observations. Establishing a dynamic learning environment requires a radical shift away from traditional instruction approach, which involves ordinary lectures, to an energetic student-directed form of instruction comprising interactive and thought provoking situations.

A situation encouraging the students to learn from each other without the intervening of any teacher is characterized as peer-instruction (Cuban, Kirkpatrick, \& Peck, 2001). It is recognized as the pairing of students to enhance the processes of learning within classrooms (Note 1) (Shapiro et al., 2013). Peer instruction method is presented theoretically as a method where students are able to acquire knowledge through observation, study, teaching of other students, or through their own experiences. The major purpose of peer instruction method is to develop the capitalizing perceptions of the students for the optimization of cognitive correspondence among the students in regards of their peers (McMaster \& Fuchs, 2016). It has been further evaluated that students' perceptions are mainly developed through informal approaches by their teachers during educational processes; also in the form of hints (Ma et al., 2014).

Engaging students in a dynamic process enables learners to construct knowledge by encouraging them to establish connections between new and previously acquired facts; promoting meaningful learning, increased attention and higher order thinking. It is probable that when students are genuinely engaged with learning materials, they can exceed expectations and requirements (Barkley, 2010). Moreover, these students are more attentive, excited, involved, and eager to participate (Hoff \& Lopus, 2014).

Contemporary educational trends have prompted college instructors to formulate various instructional methods in an attempt to produce a dynamic environment, where instructors and students are simultaneously active in improving the learning process. Furthermore, the attainment of knowledge usually needs effective listening skills 
of the students to assure their contribution during education (Biggs, 2014). Peer instruction method is also considered as an interactive pedagogy, which is helpful for students to obtain skills and knowledge through active assistance by peers (Romito, 2014). According to Zingaro (2014), peer instruction method mostly contributes in the development of self-efficacy among the students in regards of their educational progress.

Lasry, Mazur and Watkins (2008) have explained that peer instruction method is significantly helpful for the students to develop interactive skills during the lectures for better attention towards the specified concepts and approaches. In peer instruction method, a lecture consists of various mini-lectures that address key concepts pertaining to the subject being discussed. Each mini-lecture includes a short presentation concerning a key concept, followed by a multiple choice concept question. Students are also allotted short period of time to consider the problem and respond individually, followed by a group discussion concerning their responses. At the end of this discussion, students are allotted an opportunity to change their responses.

The successful implementation of peer instruction method depends on the amount of time and effort invested in the development of an effective discussion question. Regarding the first aspect, Simkins and Maier (2010) indicated that an ideal conceptual question should be short and not overly difficult, but nevertheless challenging and thought provoking. Such questions contain a sufficient amount of ambiguity to ensure that students must supply information not explicitly stated in the question itself. Additionally, questions should extend beyond memorization, and require learners to reconstruct ideas and concepts independently, which lead to increased curiosity and heightened meta-cognition. As for the second point, students ought to possess some prior knowledge of the materials before coming to class; therefore, enabling them to establish connections between new information and previously acquired concepts. Furthermore, instructors can ascertain potential difficulties that learners may face when attempting to grasp new notions or theories by establishing whether students have been exposed to a concept previously (Watkins \& Mazurr, 2010).

A peer instruction method lecture differs from its traditional counterpart in three primary respects. Firstly, in a peer instruction method lecture students are encouraged to read about a subject prior to class; therefore, it ensures that they arrive prepared to participate in various activities. This aspect differs from traditional arrangement, wherein learners read their textbooks or review lecture notes only after a topic has been discussed. In many cases, students may not do either, unless a test has been announced. Secondly, questions posted in peer instruction method lectures aim to engage the class collectively; whereas, questions in a traditional lecture target only a small number of students. While responding to a question in a peer instruction method context, each learner submits an answer, discusses it, and shares his or her rationale for a given answer. Thirdly, questions in a peer instruction method based classroom are designed to stimulate higher order thinking by requiring students to analyze, synthesize, evaluate, and provide evidence to substantiate a claim or solve a problem. Responses to these questions consequently provide an instructor with immediate feedback concerning the conceptual comprehension of his or her students, and enable him or her identify problematic concepts that should be directly addressed in a lecture. In general, a peer instruction method lecture enables students to learn from one another rather than in a one-directional manner from the instructor alone (Lee, 2010; Novak \& Patterson, 2010; Crouch et al., 2007).

The implementation of peer instruction method has many benefits including the promotion of active learning and direct student interaction. By assisting peers in the construction of knowledge, students can also cultivate higher thinking, increase reading comprehension, and develop group work and social communication skills. Furthermore, peer instruction method increases students' engagement and facilitate an enjoyable and productive classroom environment (Agbatogun, 2014; Watkins \& Mazur, 2010; Bruff, 2009). Nevertheless, instructors who choose to adopt peer instruction method may face some difficulties. For example, Fagen, Crouch, and Mazur (2002) reported that the development of proper concept tests requires a significant amount of effort; and that the sheer quantity of material that must be covered in a semester makes devoting class time specifically to concept tests difficult. Moreover, students, who are unaccustomed to active participation, are often resistant to the peer instruction method.

Yaoyuneyong and Thorton (2011) determined that peer instruction method facilitated interactive engagement in physics classrooms, which consequently led to higher learner achievement. Gok (2012) discovered that the conceptual learning of students exposed to peer instruction method in an introductory physics course exceeded that of student who was not. Akay (2011) confirmed a positive correlation between mathematics achievement and the implementation of peer instruction method; likewise, Akay (2011) found that peer instruction method had a significantly positive effect on student achievement and attitudes towards mathematics. Funchs D. and Funchs L. (2005) revealed that the implementation of peer instruction method contributed to improved word 
recognition, spelling ability, and general reading skills among young children. Furthermore, Spacco, Parris, and Simaon (2013) found statistically significant improvement in the final exam scores of students in a computing course who were exposed to peer instruction method.

Despite the potential obstacles to its implementation mentioned above, there is an abundance of evidence to suggest that peer instruction method is effective at promoting conceptual learning among students by better engaging in active learning (Gok, 2012; Watkins \& Mazur, 2010). Numerous studies have indicated that peer instruction method has a statistically significant positive effect on students' achievement when compared to traditional lecturing approaches (Steven \& Slavin, 1995; Biggs, 2014; Crouch \& Mazur, 2001; Burke \& Sass, 2006; Harvey, 2013; Spacco, Parris, \& Simaon, 2013). Nicol and Boyle (2003) found that peer instruction method-based discussions were more beneficial to students and less demanding on teachers than class-wide discussions. Likewise, multiple researchers have indicated that peer instruction method not only promotes student learning in general, but academic motivation and self-efficacy specifically, in addition to more positive attitudes towards education (Akay, 2011; Gok, 2012; Cutts, Esper, \& Simon, 2012).

\subsection{Problem Statement}

Courses concerning English teaching methodology are a core component of teacher preparation programs for prospective English instructors. Methodology courses familiarize pre-service teachers with the history of foreign language teaching, as well as different approaches to teaching English language skills. Throughout the researcher's numerous years of teaching methodology courses, it has been observed that pre-service EFL teachers often struggle to understand and differentiate between various concepts related to course topics.

In terms of improving students' comprehension of science course concepts, peer instruction method has a proven track record of effectiveness (Crouch \& Mazur, 2001; Crouch et al., 2002; Smith et al., 2009; Gok, 2012). However, no prior studies to date have examined peer instruction methods' effect on student learning in a teaching methodology course neither for English instructors, nor in a Saudi context in specifically. While earlier studies have focused on student attitudes towards courses before and after peer instruction methods' implementation, this research has examined student attitudes towards peer instruction method itself. Moreover, the study attempted to determine peer instruction method's effect on the conceptual comprehension of students enrolled in a methodology course for prospective English instructors.

\subsection{Research Questions}

This study seeks to determine the following:

1) What is the effect of Peer Instruction Method on the conceptual comprehension of pre-service teachers enrolled in a methodology course?

2) What is the impact of using Peer Instruction Method during course lectures on treatment groups?

Regarding the first question, it is not expected to find any statistically significant differences between the pre-test or post-test scores of students enrolled in methodology courses employing either peer instruction method or traditional lectures. Nevertheless, it is expected that peer instruction method will prove to be beneficial to class instruction and produce increased student engagement. Moreover, it is believed that peer instruction method would result in improved student comprehension and achievement with regard to the acquisition of new learning concepts, while also providing EFL instructors with effective techniques for encouraging peer collaboration.

\subsection{Hypotheses}

$\mathrm{H}_{01}$ : Peer instruction method will not prove to be beneficial to class instruction and produce increased student engagement

$\mathrm{H}_{\mathrm{A} 1}$ : Peer instruction method will prove to be beneficial to class instruction and produce increased student engagement

$\mathrm{H}_{02}$ : Peer instruction method will not improve the student comprehension and achievement concerning the acquisition of new learning concepts

$\mathrm{H}_{\mathrm{A} 2}$ : Peer instruction method will improve the student comprehension and achievement concerning the acquisition of new learning concepts

\subsection{Significance of the Study}

The study efficiently contributed to measure the significance of peer instruction, which is a collaborative teaching technique among the students. It enhances the learning processes of the students as a dynamic learning environment, and enables the students to eradicate the conventional learning/teaching approaches. A thoughtful 
and interactive teaching environment has been promoted by the study, which is an essential requirement of students. The study has highlighted that students are more perceived towards the peer instruction method in improving their conceptual comprehensions.

\section{Method}

\subsection{Design}

Since it was not possible to randomly assign subjects to both treatment and comparison groups, a quasi-experimental design was adopted. The quasi-experimental design is a method where researcher selects people in groups on which the research variables are tested (Note 2). Quasi-experimental method is more or less similar to experimental design or randomized control trials, but there is no random assignment to control or treatment (Miller H. \& Miller J., 2010). It entailed administrating a pre- and post-test to treatment and comparison groups, who were taught identical course content. The treatment group $(\mathrm{N}=41)$ received instruction from peers and their teacher; whereas, the comparison group $(\mathrm{N}=37)$ received only teacher-directed instruction. Peer instruction sessions were conducted once weekly for a 16 week period.

\subsection{Sample}

Seventy eight female Saudi students aged between 23 and 25 years old were selected as sample. The students were enrolled in the Graduate Diploma of Education Program at Taibah University, which targets graduates lacking a background in education who wish to obtain teaching qualifications. The programs' courses and training initiatives address educational approaches, curriculum design, and instructional techniques.

\subsection{Research Instruments}

Data were collected using a pre-post conceptual comprehension methodology test. A questionnaire was designed to assess the attitudes of students towards using peer instruction method in learning about teaching methodologies. According to previous researchers, there are several instruments (such as open-ended questions, detailed interviews, and multiple choice questions) available for assessing the effectiveness of specific conceptual learning (Hestenes, Wells, \& Swackhamer, 1992).

The aforementioned pre-post conceptual test was developed by the researcher. While designing the conceptual tests, the items were selected that required short answers from the course to ensure conceptual learning of research methods and their application. A list of objectives to be measured and a table of specifications were presented to specialists in foreign language teaching methods. These objectives were measured to seek their opinion on the validity of the instrument and to identify whether the instrument is parallel with the teaching objectives, and can be used for setting conceptual learning or not. The responses and suggestions made by these specialists were used for revising the concept test. Furthermore, for checking the validity and reliability of the test, the content was checked for its comprehensiveness, relativeness and objectivity.

The questionnaire, which was also created by the researcher, comprised (26) items based on a five-point Likert-scale wherein $5=$ strongly agree, $4=$ agree, $3=$ neutral, $2=$ disagree, and $1=$ strongly disagree. This questionnaire was developed with the help of previous studies (for example Akay, 2011; Gok, 2012). Negative items were reversed into positive ones upon the processing of data, and each participant's expected score ranged between (26 and 130 points). A panel of specialists was appointed to examine the appropriateness of the questionnaire's items, and revisions were made based on their recommendations. For checking the reliability of the test, Cronbach's alpha was conducted, and its reliability was determined to be high (.950).

\subsection{Classroom Environment}

Completing a methodology course is mandatory for students enrolled in the Graduate Diploma of Education program, which leads students to be able to distinguish between an approach, method, and technique; to identify the main features, advantages, and disadvantages of traditional English teaching methods; to recognize key characteristics of various modern teaching methods; and to identify different aspects of language skills and elements in order to develop lesson plans and subsequently teach such language skills and elements.

Prior to the experiment, the instructor familiarized the treatment group with how peer instruction methods should be conducted during actual lectures, including a description of students' roles and responsibilities. Members of the treatment group were invited to join a group for the course hosted on Edmodo (see Figure 1), a website that provides schools and teachers with communication, collaboration, and coaching tools; students also downloaded that website's accompanying mobile applications, which enabled them to conveniently access the course group during class session. Materials, notes, assignments and polls were made available by the instructor on the course's page, and students were taught how to complete pre-class assignments online and upload them. Before 
class, students were required to read lecture notes and watch presentations and video clips posted on the course group.

Lectures commenced with a short presentation outlining a key concept; students then responded to a conceptual multiple-choice question that was posted on the course page. Participants were afforded some time to contemplate the question before individually responding to it; after submitting an answer, students were urged to discuss their responses with peers (Figure 1). During this process, participants were allowed to freely mingle with classmates while sharing the underlying rationale for their respective answers (Figure 1). This was followed by a class discussion, wherein the instructor functioned as a guide and moderator. After the discussion concluded, the students were given an opportunity to submit a different response (Figure 1). Time was also set aside by the instructor to discuss students' different responses and their implications. Later, the percentage of correct responses was calculated. If the percentage of correct answers was high, the instructor briefly explained the concept and then proceeded to discuss another key idea. Conversely, if the percentage was low, additional time was devoted to ensure students' understanding of a problematic concept.

Based on a personal experience, it has been determined that a successful peer instruction method implementation depends largely on pre-class reading and in-class engagement. It is imperative for the students to enter the classroom with some degree of knowledge concerning unfamiliar topic, as greater preparedness results in more productive discussions. By extension, elevated engagement leads to greater benefits on the learners' behalf. Hence, a grading policy was implemented, which rewarded preparedness and engagement rather than the selection of correct responses.

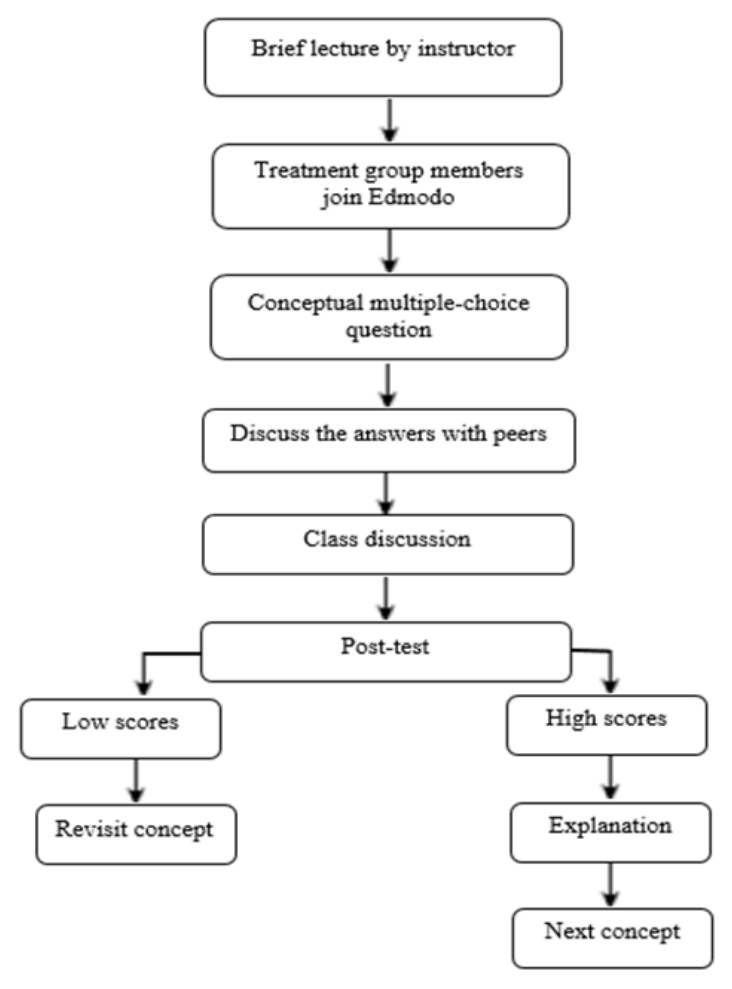

Figure 1. Flow chart of the process

\subsection{Procedures}

The pre-test was administered to both the treatment and comparison groups prior to the experiments' commencement, in order to determine the amount of homogeneity between them. An analysis of the data has not revealed any statistically significant differences among either group in terms of conceptual achievement. Treatment was conducted during the first semester of academic year 2015 and spanned 16 weeks. Following the experiment, the post-test was administrated to members of both groups, while the attitudinal questionnaire was administrated to the treatment group alone. The scores collected by attitudinal questionnaire were recorded and 
entered into data sheet of SPSS 20.0 (Statistical Package for the Social Sciences). T-test was used for analyzing the data collected. It helped in testing the means of treatment and control groups in order to identify the impact of peer instruction method on pre-service teachers. The responses of the students in treatment group were evaluated during the application process by taking students responses on the topics discussed.

\section{Results}

\subsection{Findings Regarding the First Research Question}

To examine whether the peer instruction method affected student achievement, the conceptual comprehension of both groups was measured before and after instruction took place. The results (see Table 1) indicated that there was no statistically significant difference $(\mathrm{t}=.181$; $\mathrm{sig}=.857)$ between the average scores of either group; hence, validating the first half of the study's null hypothesis (i.e., no significant difference would be found between the pre-test scores of students exposed to peer instruction method and traditional lecture).

The peer instruction method group's mean post-test score was $M=37.219$; whereas, the regular instruction group's mean score was $\mathrm{M}=31.216$, and thus, statistically different $\left(\mathrm{t}=7.901 ; \mathrm{sig}=000^{* *}\right)$. Accordingly, the peer instruction method group achieved significantly higher results; thereby, invalidating the second half of the study's null hypothesis (i.e., no significant difference would be found between the post-test scores of students exposed to peer instruction method and traditional lectures) (Table 1).

To calculate peer instruction method's effect size on conceptual understanding: The Cohen's d value and effect size correlation were computed based on the t-test value between subjects t-test and the degrees of freedom. The findings showed that $d=1.81$. Hence, peer instruction method exhibited a very large effect size among students in the treatment group.

Table 1. Analysis of the pre- and post-test scores for both groups

\begin{tabular}{cccccccccc}
\hline Test & Group & $\mathrm{N}$ & Mean & $\mathrm{SD}$ & $\mathrm{F}$ & $\mathrm{sig}$ & $\mathrm{t}$ & $\mathrm{df}$ & sig \\
\hline Pre-test & Treatment & 41 & 19.536 & 3.1551 & .000 & .985 & .181 & 76 & .857 \\
& Comparison & 37 & 19.405 & 3.2528 & & & & & \\
\multirow{3}{*}{ Post-test } & Treatment & 41 & 37.219 & 2.5837 & & & & & \\
& Comparison & 37 & 31.216 & 4.0355 & 7.151 & .009 & 7.901 & 76 & $.000^{* *}$ \\
\hline
\end{tabular}

The results from Table 2 for the group variable indicated that there was significant difference between posttest and group variable, which means that level of significance, is less than 0.05 . Furthermore, grand mean from Table 3 has estimated the estimated marginal mean for both groups to identify the mean response, which illustrated that experimental group has higher mean as compared to control group after adjusting for pretest.

Table 2. Analysis results of ANCOVA for both groups

\begin{tabular}{lrrrrrr}
\hline Source & $\begin{array}{r}\text { Type III Sum of } \\
\text { Squares }\end{array}$ & d.f & Mean Square & F & Sig. & $\begin{array}{r}\text { Partial Eta } \\
\text { Squared }\end{array}$ \\
\hline Corrected Model & $1113.452^{\mathrm{a}}$ & 2 & 556.726 & 94.732 & .000 & .716 \\
Intercept & 804.851 & 1 & 804.851 & 136.952 & .000 & .646 \\
pretest & 412.529 & 1 & 412.529 & 70.195 & .000 & .000 \\
group & 678.519 & 1 & 678.519 & 115.456 & & .606 \\
Error & 440.766 & 75 & 5.877 & & & \\
Total & 93705.000 & 78 & & & & \\
Corrected Total & 1554.218 & 77 & & & & \\
\hline
\end{tabular}

a. R Squared $=.716$ (Adjusted R Squared $=.709)$. 
Table 3. Estimated marginal mean for both groups

\begin{tabular}{|c|c|c|c|c|}
\hline \multirow[t]{2}{*}{ Group } & \multirow[t]{2}{*}{ Mean } & \multirow[t]{2}{*}{ Std. Error } & \multicolumn{2}{|c|}{$95 \%$ Confidence Interval } \\
\hline & & & Lower Bound & Upper Bound \\
\hline treatment & $37.174^{\mathrm{a}}$ & .379 & 36.420 & 37.929 \\
\hline control & $31.266^{\mathrm{a}}$ & .399 & 30.472 & 32.060 \\
\hline
\end{tabular}

a. Covariates appearing in the model are evaluated at the following values: pretest $=19.4744$.

\subsection{Findings Regarding the Second Research Question}

Table 4 showed statistical descriptive analysis of the attitudinal questionnaire administered to the treatment group at the semester's end, which was designed to gain insight into their feelings concerning peer instruction method. A sample t-test was also conducted to compare the responses' means to each item with a value of 3 , which denotes neutral attitude.

Table 4. Analysis results of the attitudinal questionnaire administered to the treatment group

\begin{tabular}{|c|c|c|c|c|c|c|c|c|c|}
\hline Item & $\mathrm{N}$ & Mean & SD & t. & Item & $\mathrm{N}$ & Mean & SD & t. \\
\hline 1 & 41 & 4.5500 & .71432 & $40.28 * *$ & 14 & 41 & 3.9750 & .91952 & $27.34 * *$ \\
\hline 2 & 41 & 4.4500 & .78283 & $35.95^{* *}$ & 15 & 41 & 4.3250 & .94428 & $28.96^{* *}$ \\
\hline 3 & 41 & 4.4500 & .67748 & $41.54 * *$ & 16 & 41 & 4.5000 & .81650 & $34.85 * *$ \\
\hline 4 & 41 & 4.3250 & .76418 & $35.79^{*}$ & 17 & 41 & 4.4500 & .78283 & $35.95 * *$ \\
\hline 5 & 41 & 4.1250 & .99195 & $26.30 * *$ & 18 & 41 & 4.3750 & .80662 & $34.30 * *$ \\
\hline 6 & 41 & 3.4000 & 1.3737 & $15.65^{* *}$ & 19 & 41 & 4.4500 & .67748 & $41.54 * *$ \\
\hline 7 & 41 & 4.2500 & .92681 & $29.00 * *$ & 20 & 41 & 4.4500 & .63851 & $44.07 * *$ \\
\hline 8 & 41 & 4.2500 & .98058 & $27.41 * *$ & 21 & 41 & 3.9500 & .95943 & $26.03 * *$ \\
\hline 9 & 41 & 4.2500 & .66986 & $40.12 * *$ & 22 & 41 & 4.3250 & .85896 & $31.84 * *$ \\
\hline 10 & 41 & 4.0000 & 1.03775 & $24.37 * *$ & 23 & 41 & 4.3750 & .89693 & $30.85 * *$ \\
\hline 11 & 41 & 4.0000 & 1.03775 & $24.37 * *$ & 24 & 41 & 4.2750 & .93336 & $28.96^{* *}$ \\
\hline 12 & 41 & 4.2000 & .82275 & $32.28 * *$ & 25 & 41 & 4.3000 & .79097 & $34.38 * *$ \\
\hline 13 & 41 & 4.2000 & .68687 & $38.67 * *$ & 26 & 41 & 4.5250 & 67889 & $42.15^{* *}$ \\
\hline Total & 41 & 4.258 & 0.5772 & & & & & & \\
\hline
\end{tabular}

$* * \mathrm{p}<0.00$.

The results of the questionnaire's analysis revealed high mean scores ranging between 4.5500- and 3.4000. The highest mean score was obtained for Item $1(\mathrm{M}=4.5500)$, showing that $92 \%$ of the participants believed that peer instruction method created a supportive classroom environment. The second highest mean score was obtained for Item $26(\mathrm{M}=4.5250)$, which indicates that roughly $95 \%$ of the treatment group intends to utilize peer instruction method in their future teaching career. Item (16) acquired the third highest mean score $(\mathrm{M}=$ 4.5000), signifying that $92.5 \%$ of the participants believed that pre-class reading afforded them with sufficient knowledge to participate in peer instruction method-based lectures. Items 2, 3, 17, 19, and 20 obtained an identical mean score $(\mathrm{M}=4.4500)$, and collectively achieved a fourth place ranking, thus, revealing that $90-95 \%$ of the treatment group either agreed or strongly agreed that peer instruction method promoted group discussion, strengthened self-responsibility, made key concepts more clear, and encouraged participants to exchange viewpoints concerning course concepts (Table 4).

Likewise, items 18 and 23 possessed equivalent mean score $(\mathrm{M}=4.3750)$, and therefore, obtained a fifth place ranking; this result indicates that $90-92 \%$ of the participants believed that peer instruction method increased lecture enjoyability, and led to the easier acquisition of key concepts. Items 4,15 , and 22 also attained an identical mean score $(\mathrm{M}=4.3250)$, thereby placing it at sixth place as shown in Table 2 . This finding reveals that 
most treatment group members are at sixth in rank indicating that the majority of the sample members $87.5-92.5 \%$ agreed that pre-class reading improves one's understanding of key concepts and that peer instruction method -based activities increase student interaction.

Although, Item 6 obtained the lowest mean score $(M=3.4000)$, it was nonetheless higher than the midpoint. Of the treatment group's members, $65 \%$ preferred peer instruction method-based activities; whereas, $30 \%$ favored individual activities. Item 14 obtained the second lowest mean score $(\mathrm{M}=3.9750)$; thus, demonstrating that only $12.5 \%$ of those surveyed disagreed with the notion that peer discussion contributes to improved learning. In general, the treatment group harboured positive attitudes towards peer instruction method, and found it beneficial in enabling them to comprehend key course concepts (Table 5).

\section{Discussion}

This research examined peer instruction method's effect on the conceptual comprehension of 78 pre-service teachers enrolled in a graduate-level methodology course at Taibah University in Medina, Saudi Arabia. A quasi-experimental method was adopted based on a pre and post test design, and peer instruction method was used to teach course concepts to the treatment group; whereas, the comparison group was exposed to traditional teaching approach. Statistical analysis invalidated the second half of the null hypothesis (i.e., no significant difference would be found between the post-test scores of students exposed to peer instruction method and traditional lectures), as there were statistically significant differences between both groups' average mean post-test scores.

The effect size was calculated for further verification of the first hypothesis. To calculate the effect size of the peer instruction method, the Cohen's d value and effect size correlation was computed using the $t$ test value for between subject's $t$ test and the degrees of freedom. The resultant Cohen's $d$ value was 1.81 , and the effect size $r$ was 0.67 . This finding showed that peer instruction method was effective and had a very large effect size in enhancing conceptual understanding. Furthermore, statistical analysis of the questionnaire results revealed that participants harboured positive attitudes towards peer instruction method, thereby satisfactorily answering the study's second research question.

These findings are in agreement with similar studies that focused on peer instruction method in mathematics and physics education. The results of this study shows that peer-based instruction method prove to be more effective for participants to learn and develop their skills. Apart from mastering in skill development, peer instruction method also extracts positive outcomes in areas of communication, accountability, motivation and social interactions. This also helped participants in developing reflective knowledge-building skills and knowledge telling. For example how well they can communicate with others and how well do they know. Furthermore, it was observed from the findings that peer instruction method increases the understanding of different concepts among students and also increases the interest. This aspect suggested that students who were initially having problem in understanding a concept were able to apply the knowledge gained during the group discussions and were also able to enhance their overall results. This may be because when students discuss in other groups, they are able to make more sense of the information which improves their performance.

A study conducted by Gok (2014) analyzed the influence of peer instructions on the performance considering conceptual learning and problem solving. The students were recruited as per the treatment and control group. The treatment group was instructed with peer instruction method; whereas, the control group was provided with the traditional instructions. The results indicated that peer instruction had a positive influence on the conceptual learning of the students as compared to the conventional instructions. The students also changed their perception on solving the problems and understanding the ideas. It has been observed that peer instruction method is helpful to connect the solutions quantitatively with related solutions (Crawley et al., 2014).

Zingaro and Porter (2014) also demonstrated that Peer instruction method is a collaborative pedagogical practice in classes. This method has shown significant improvement in the final examination performance of the students over conventional lecture. Failure rates were also observed decreasing and students were being retained because of peer instruction method in teaching. Peer instruction method actively involves the students in enhancing their own understanding from the explanation of the instructor and construct their own learning patterns (Simon et al., 2013). This method is now being implemented in a broad range of mathematics and science courses at the secondary level of education and colleges (Mazur, 2013).

It is believed that the above mentioned results are attributable to numerous factors. Peer instruction method produces a supportive learning environment wherein students assist each other throughout the learning process, and collaborate in order to construct knowledge and reach an understanding concerning key concepts. Since, 
students receive immediate feedback from peers, it is not necessary for them to wait for an instructor to provide feedback which results in the obtainment of a deeper understanding. Such a learning environment is less threatening than a traditional classroom configuration, because it permits students to ask their peer's questions, share various solutions, and respond to different viewpoints. In that regard, learners in a peer instruction method classroom are less fearful of making mistakes, since the instructor's role as gatekeeper of knowledge is significantly reduced. Moreover, the study's use of an online voting system afforded students an opportunity to participate equally, while also adding an element of fun and excitement to the class. Also, the use of pre-reading assignments enabled students to familiarize themselves with materials prior to attending a lecture; this, in turn, provided learners with a sufficient amount of background knowledge to partake in discussions concerning a given topic with their peers.

The purpose of this research was to analyze the effect of Peer Instruction Method on the conceptual comprehension of pre-service teachers enrolled in a methodology course. The study was based on quasi-experimental research design, where peer instruction session was conducted for 16 weeks. It was concluded from the research that students were better facilitated through peer instruction environment because they were able to ask as many questions, risk untested speculations and express opinions which highly contributed in learning process. It was observed that it was easier for peer-instructor to understand the learning issues and problems than teacher who probably did not experienced recently as a student. Therefore, it has been concluded that peer instruction method is a cooperative and collaborative teaching strategy among students which stimulates the learning process for students.

\subsection{Future Recommendations}

Based on the conclusion, further studies can be conducted by comparing the peer-based instructions with traditional methods. The effectiveness of peer-based instructions in different fields, such as science, mathematics, engineering, etc. can also be the prime focus of future studies. Researchers can also focus on using concept test in analyzing the effectiveness of peer-based instructions on pre-service science and math teachers. Future research should be focusing on replication of different populations and different designs for example conducting sessions more frequently for a longer period of time, which includes various within-subjects measures. On a more practical note, as teachers in classrooms everywhere consider how to excite and motivate their students to learn and grow, peer-based instruction is undoubtedly one choice that should be explored.

\section{Acknowledgements}

The author of this study would like to extend sincere gratitude and appreciation to all the people who contributed for the accomplishment of this task. The research process required higher level of commitment and dedicated efforts, and the facilitators were a source of motivation and enrichment with their invaluable contribution in this study. The author certifies that she has no affiliations with or involvement in any organization or entity with any financial or non-financial interest in the subject matter or materials discussed in this manuscript.

\section{References}

Agbatogun, A. O. (2014). Developing learners' second language communicative competence through active learning: Clickers or communicative approach. Educational Technology \& Society, 17(2), 257-269.

Akay, G. (2011). The effect of peer instruction method on the eighth grade students' mathematics achievement in transformation geometry and attitudes towards mathematics (Master's thesis). Middle East Technical University, Ankara, Turkey.

Barkley, E. F. (2010). Student engagement techniques: A handbook for college faculty. Jossey-Bass.

Biggs, J. (2014). Constructive alignment in university teaching. HERDSA Review of Higher Education, 1(5), $5-22$.

Bruff, D. (2009). Teaching with classroom response systems: Creating active learning environments. Jossey-Bass.

Burke, M., \& Sass, T. (2006). Classroom peer effects and student achievement.

Crawley, E. F., Malmqvist, J., Östlund, S., Brodeur, D. R., \& Edström, K. (2014). Teaching and Learning. In Rethinking Engineering Education (pp. 143-163). Springer International Publishing. https://doi.org/10.1007/978-3-319-05561-9_6

Crouch, C. H., \& Mazur, E. (2001). Peer instruction: Ten years of experience. American Association of Physics Teachers, 69(9), 970-975. https://doi.org/10.1119/1.1374249 
Crouch, C. H., Watkins, J., Fagen, A. P., \& Mazur, E. (2007). Peer instruction: Engaging students one-on-one, all at once. Retrieved January 19, 2016, from http://mazur.harvard.edu/publications.php?function=display\&rowid $=537$

Cuban, L., Kirkpatrick, H., \& Peck, C. (2001). High access and low use of technologies in high school classrooms: Explaining an apparent paradox. American Educational Research Journal, 38(4), 813-834. https://doi.org/10.3102/00028312038004813

Cutts, Q., Esper, S., \& Simon, B. (2012). Exploratory home-works: An active learning tool for textbook reading. In Proceedings of the Ninth Annual International Conference on International Computing Education Research (pp. 105-110). New York: ACM.

Fagen, A., Crouch, C., \& Mazur, E. (2002). Peer instruction: Results from a range of classrooms. The Physics Teacher, 40, 206-209. https://doi.org/10.1119/1.1474140

Funchs, D., \& Funchs, L. S. (2005). Peer-assisted learning strategies: Promoting word recognition, fluency, and reading comprehension in young children. The Journal of Special Education, 93(1), 34-44. https://doi.org/10.1177/00224669050390010401

Gok, T. (2012). The effect of peer instruction on students' conceptual learning and motivation. Asia-Pacific Forum on Science Learning and Teaching, 13(1), 1-17.

Gok, T. (2014). Peer Instruction In The Physics Class Room: Effects On Gender Difference Performance, Conceptual Learning, and Problem Solving. Journal of Baltic Science Education, 13(6).

Harvey, N. (2013). The effect of peer instruction on ninth grade students' conceptual Boston understanding of force and motion (Doctoral Dissertation). Louisiana State University, Rouge, Louisiana.

Hestenes, D., Wells, M., \& Swackhamer, G. (1992). Force concept inventory. Physics Teacher, 30, 141-158. https://doi.org/10.1119/1.2343497

Hoff, J., \& Lopus, J. (2014). Does student engagement affect student achievement in high school economics classes? Paper presented at the Annual Meeting of the Allied Social Science Association, Philadelphia, PA. Retrieved from January 18, 2016, from http://mazur.harvard.edu/sentFiles/mazurpubs_573.pdf

Lasry, N., Mazur, E., \& Watkins, J. (2008). Peer instruction: From Harvard to the two-year college. American Journal of Physics, 76(11), 1066-1069. https://doi.org/10.1119/1.2978182

Lee, I. (2010). The effect of learning motivation, total quality teaching and peer-assisted learning on study achievement: Empirical analysis from vocational universities or colleges' students in Taiwan. The Journal of Human Resource and Adult Learning, 6(2), 56-73.

Ma, W., Adesope, O. O., Nesbit, J. C., \& Liu, Q. (2014). Intelligent tutoring systems and learning outcomes: A meta-analysis. Journal of Educational Psychology, 106(4), 901. https://doi.org/10.1037/a0037123

Mazur, E. (2013). Peer instruction.

McMaster, K. L., \& Fuchs, D. (2016). Classwide intervention using peer-assisted learning strategies. In Handbook of Response to Intervention (pp. 253-268). Springer US. https://doi.org/10.1007/978-1-4899-7568-3_15

Miller, H. V., \& Miller, J. M. (2010). Community in-reach through jail reentry: Findings from a $\begin{array}{llll}\text { quasi-experimental } \quad \text { design. } & \text { Sustice }\end{array}$ https://doi.org/10.1080/07418825.2010.482537

Nicol, D., \& Boyle, J. (2003). Peer Instruction versus class-wide discussion in large classes: A comparison of two interaction methods in the wired classroom. Studies in Higher Education, 28(4), 458-472. https://doi.org/10.1080/0307507032000122297

Novak, G., \& Patterson, E. (2010). An introduction to just-in-time teaching (JiTT). In S. Simkins, \& M. Maier (Eds.), Just-in-time teaching (pp. 39-62).

Romito, A. (2014). Peer assisted learning. In R. Mehay (Ed.), The Essential Handbook for GP Training and Education.

Shapiro, C., Ayon, C., Moberg-Parker, J., Levis-Fitzgerald, M., \& Sanders, E. R. (2013). Strategies for Using Peer-assisted Learning Effectively in an Undergraduate Bioinformatics Course. Biochemistry and Molecular Biology Education, 41(1), 24-33. https://doi.org/10.1002/bmb.20665 
Simkins, S., \& Maier, M. (2010). Just-in-time teaching. VA: Stylus Publication.

Simon, B., Parris, J., \& Spacco, J. (2013, March). How we teach impacts student learning: Peer instruction vs. lecture in CS0. In Proceeding of the 44th ACM technical symposium on Computer science education (pp. 41-46). ACM. https://doi.org/10.1145/2445196.2445215

Smith, M. K., Wood, W. B., Adams, W. K., Wieman, C., Knight, J. K., Guild, N., \& SU, T. (2009). Why peer discussion improves student performance on in-class concept questions. Science, 323(5910), 122-124. https://doi.org/10.1126/science.1165919

Spacco, J., Parris, J., \& Simaon, B. (2013). How we teach impacts student learning: Peer instruction vs. lecture in CS0. In Proceedings of the 44thTechnical Symposium on Computer Science Education (pp. 41-46). NewYork: ACM.

Watkins, J., \& Mazurr, E. (2010). Just-in-time teaching and peer instruction. In S. Simkins, \& M. Maier (Eds.), Just-in-time teaching (pp. 39-62). Sterling, V A: Stylus Publishing.

Yaoyuneyong, G., \& Thorton, A. (2011). Combining peer instruction and audience response systems to enhance academic performance, facilitate active learning and promote peer assisted learning communities. International Journal of Fashion Design, Technology and Education, 4(2), 127-139. https://doi.org/10.1080/17543266.2011.564210

Zingaro, D. (2014). Peer instruction contributes to self-efficacy in CS1. In Proceedings of the 45th ACM technical symposium on Computer science education (pp. 373-378). ACM. https://doi.org/10.1145/2538862.2538878

Zingaro, D., \& Porter, L. (2014). Peer Instruction in computing: The value of instructor intervention. Computers \& Education, 71, 87-96. https://doi.org/10.1016/j.compedu.2013.09.015

\section{Notes}

Note 1. The teaching method Peer Instruction (PI) -peer education method- aims to explore the interaction between students during class and emphasize fundamental concepts of class. The lectures are replaced by short presentations, dealing with the main points of the topic covered in class, followed by conceptual tests aimed at emphasizing the concepts. During the classes, students have a few minutes to answer the questions and then discuss them with colleagues, trying to convince each other, the right answer. The process encourages students to think through convincing arguments, providing affordable ways to understand the concept.

Note 2. The quasi-experimental methods flexibilize the conditions imposed by probability distributions and statistical inferences for the population, imposed by pure experimental research models, transferring the center of attention of "cause and effect" of the temporal priority for association between variables. There is only a group of individuals considered eligible before and after program implementation to review, or, alternately, two groups from the same eligible population: an extracted prior to program implementation and after another. This design method has been generally helpful to review pilot projects or national programs implemented at any given time. The main critical aspect of this methodology involves the difficulty in interpreting correctly the changes between two time periods. Another critical aspect relates the imbalances between the two groups. The selection of the two groups held in different times, of course result in different factors affecting the results.

\section{Appendix A}

Table A1: Questionnaire

\begin{tabular}{llccc}
\hline No & \multicolumn{1}{c}{ Statements } & $\begin{array}{c}\text { Strongly } \\
\text { agree }\end{array}$ & $\begin{array}{c}\text { Agree } \\
\text { Neutral }\end{array}$ & $\begin{array}{c}\text { Disagree } \\
\text { Strongly } \\
\text { disagree }\end{array}$ \\
\hline 1 & Peer Instruction (PI )creates a supportive atmosphere in class & & \\
& PI gives all students a chance to participate in class & & \\
2 & The use of PI promotes discussion among students & & \\
3 & I think that PI strengthens students' sense of responsibility & & \\
\hline
\end{tabular}


$4 \quad$ Using PI makes the course interesting

5 PI method motivates me to learn

$6 \quad$ I prefer individual activities to PI

7 PI improves students' social skills

$8 \quad$ PI increases interaction among students

$9 \quad$ PI is a flexible method of learning

10 PI creates a friendly relationship among students

11 PI saves students time and effort

12 I think that my peers help me to carry out activities effectively

13 I think that students should offer help to improve their peers' learning

14 Oral discussion with peers does not help students to learn

15 Pre-class reading improves my understanding of course key concepts

16 Pre-class reading provides me with knowledge to participate in online PI activities

17 Online PI activities (polling questions, discussion, writing comments) promote better understanding of key concepts

18 Online PI activities makes key concepts easier to learn

19 Using online PI activities make key concepts clearer

20 Online PI activities encourage me to exchange views and ideas about course concepts

21 Using online PI activities does not improve my understanding of key concept

22 Using online PI activities increases interaction between students and the teacher in class.

23 Using online PI activities make the class more enjoyable

24 Participating in online PI activities helps me understand how peers think

25 I like learning other courses using PI method

26 I think I will use PI method in my future career

Table A2. Sample item test descriptive

\begin{tabular}{lccccr}
\hline \multicolumn{5}{c}{ Descriptive Statistics } \\
\hline st1 & $\mathrm{N}$ & Range & Sum & Mean & Std. Deviation \\
st2 & 40 & 3.00 & 182.00 & 4.5500 & .71432 \\
st3 & 40 & 4.00 & 178.00 & 4.4500 & .78283 \\
st4 & 40 & 2.00 & 178.00 & 4.4500 & .67748 \\
st5 & 40 & 3.00 & 173.00 & 4.3250 & .76418 \\
st6 & 40 & 4.00 & 165.00 & 4.1250 & .99195 \\
st7 & 40 & 4.00 & 136.00 & 3.4000 & 1.37375 \\
st8 & 40 & 4.00 & 170.00 & 4.2500 & .92681 \\
st9 & 40 & 4.00 & 170.00 & 4.2500 & .98058 \\
\hline
\end{tabular}




\begin{tabular}{|c|c|c|c|c|c|}
\hline st10 & 40 & 3.00 & 160.00 & 4.0000 & 1.03775 \\
\hline st11 & 40 & 3.00 & 160.00 & 4.0000 & 1.03775 \\
\hline st12 & 40 & 3.00 & 168.00 & 4.2000 & .82275 \\
\hline st13 & 40 & 3.00 & 168.00 & 4.2000 & .68687 \\
\hline st14 & 40 & 3.00 & 159.00 & 3.9750 & .91952 \\
\hline st15 & 40 & 4.00 & 173.00 & 4.3250 & .94428 \\
\hline st16 & 40 & 4.00 & 180.00 & 4.5000 & .81650 \\
\hline st17 & 40 & 4.00 & 178.00 & 4.4500 & .78283 \\
\hline st18 & 40 & 4.00 & 175.00 & 4.3750 & .80662 \\
\hline st19 & 40 & 3.00 & 178.00 & 4.4500 & .67748 \\
\hline st20 & 40 & 3.00 & 178.00 & 4.4500 & .63851 \\
\hline st21 & 40 & 4.00 & 158.00 & 3.9500 & .95943 \\
\hline st22 & 40 & 4.00 & 173.00 & 4.3250 & .85896 \\
\hline st23 & 40 & 4.00 & 175.00 & 4.3750 & .89693 \\
\hline st24 & 40 & 4.00 & 171.00 & 4.2750 & .93336 \\
\hline st25 & 40 & 4.00 & 172.00 & 4.3000 & .79097 \\
\hline st26 & 40 & 3.00 & 181.00 & 4.5250 & .67889 \\
\hline Valid N (listwise) & 40 & & & & \\
\hline
\end{tabular}

Table A3. Reliability statistics for sample items

\begin{tabular}{lccc}
\hline & Reliability Statistics & & \\
\hline Cronbach's Alpha & Part 1 & Value & .884 \\
& & N of Items & $13^{\mathrm{a}}$ \\
& Part 2 & Value & .942 \\
& & N of Items & $13^{\mathrm{b}}$ \\
Correlation Between Forms & Total N of Items & & .784 \\
Spearman-Brown Coefficient & & & .879 \\
& Equal Length & & .879 \\
Guttman Split-Half Coefficient & Unequal Length & & .877 \\
\hline
\end{tabular}

a. The items are: st1, st2, st3, st4, st5, st6, st7, st8, st9, st10, st11, st12, st13.

b. The items are: st14, st15, st16, st17, st18, st19, st20, st21, st22, st23, st24, st25, st26.

\section{Copyrights}

Copyright for this article is retained by the author(s), with first publication rights granted to the journal.

This is an open-access article distributed under the terms and conditions of the Creative Commons Attribution license (http://creativecommons.org/licenses/by/4.0/). 